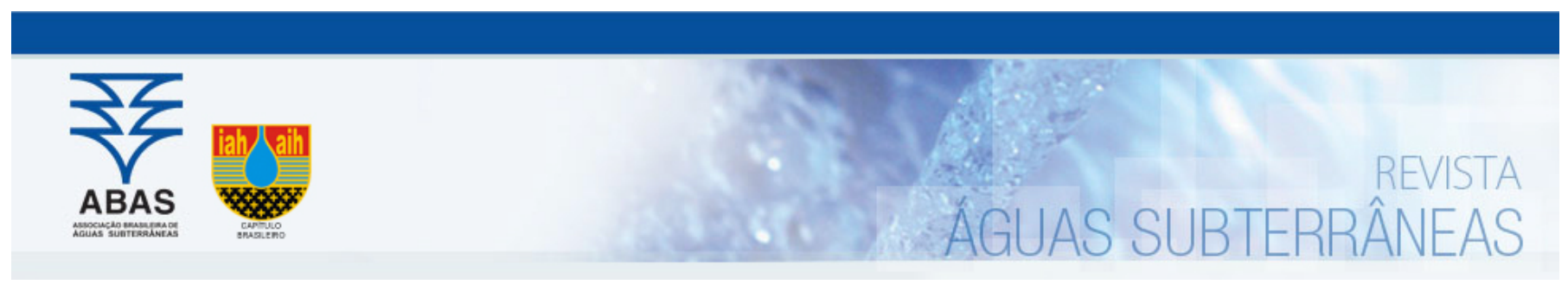

\title{
Mapeamento do risco à contaminação do sistema aquífero Serra Geral no município de Chapecó (SC)
}

\section{Mapping the contamination risk of the Serra Geral aquifer system in the municipality of Chapecó (SC)}

\author{
Mirianne Ugolini Goulart Soares ${ }^{1}$; Aline de Almeida Mota ${ }^{\bowtie}$ \\ 1 Universidade Federal da Fronteira Sul (UFFS), Chapecó, SC, Brasil. \\ $\bowtie$ miry.7@hotmail.com; aline.mota@uffs.edu.br
}

\begin{tabular}{|c|c|}
\hline & Resumo \\
\hline $\begin{array}{l}\text { Palavras-chave: } \\
\text { Vulnerabilidade. } \\
\text { Perigo. } \\
\text { Planejamento. } \\
\text { GOD. } \\
\text { POSH. }\end{array}$ & $\begin{array}{l}\text { O objetivo deste trabalho foi mapear a vulnerabilidade, o perigo e o risco à contaminação do Sistema Aquífero Serra Geral no } \\
\text { município de Chapecó, por meio da aplicação dos métodos GOD, POSH e álgebra de mapas, respectivamente. Para isso, } \\
\text { foram utilizadas informações da hidrogeologia, pedologia e nível estático dos poços perfurados na região e cadastrados no } \\
\text { Sistema de Informações de Águas Subterrâneas. Por meio do método GOD, estimou-se a vulnerabilidade do Sistema Aquífero } \\
\text { Serra Geral como baixa em aproximadamente } 90 \% \text { da área município. Entretanto, } 57 \% \text { da área do município e } 83 \% \text { do perí- } \\
\text { metro urbano foram classificados como de perigo elevado. Isso faz com que aproximadamente metade da área do Sistema } \\
\text { Aquífero Serra Geral no município tenha risco alto, e no perímetro urbano essa porcentagem é ainda maior, } 71 \% \text {. Estes resul- } \\
\text { tados evidenciam a necessidade de planejamento adequado no que diz respeito à localização tanto de novos poços quanto } \\
\text { de atividades antrópicas. Os mapas gerados podem ser utilizados como ferramenta para o planejamento territorial do muni- } \\
\text { cípio. } \\
\text { Abstract }\end{array}$ \\
\hline $\begin{array}{l}\text { Keywords: } \\
\text { Vulnerability. } \\
\text { Hazard. } \\
\text { Planning. } \\
\text { GOD. } \\
\text { POSH. }\end{array}$ & $\begin{array}{l}\text { The objective of this work was to map the vulnerability, hazard and risk to contamination of the Serra Geral Aquifer System in } \\
\text { the municipality of Chapecó, by applying the GOD, POSH and map algebra methods, respectively. For this, information on } \\
\text { hydrogeology, pedology and static level of wells drilled in the region and registered in the Groundwater Information System } \\
\text { was used. Through the GOD method, the vulnerability of the Serra Geral aquifer system was estimated as low in approximately } \\
90 \% \text { of the municipal area. However, } 57 \% \text { of the area of the municipality and } 83 \% \text { of the urban perimeter were classified as } \\
\text { high hazard. As a result, approximately half of the Serra Geral Aquifer System area in the municipality has a high risk, and in } \\
\text { the urban perimeter this percentage is even higher, } 71 \% \text {. These results demonstrate the need for adequate planning about } \\
\text { the location of both new wells and anthropogenic activities. The maps elaborated can be used as a tool for the territorial } \\
\text { planning of the municipality. }\end{array}$ \\
\hline
\end{tabular}

Revisado por pares.

\section{INTRODUÇÃO}

Embora sejam progressivamente explotados, os aquíferos se apresentam como uma reserva de recursos hídricos estratégica, correspondendo a aproximadamente $97 \%$ da água doce disponível para uso, em geral com boa qualidade para consumo.

Entretanto, algumas atividades antrópicas provocam a contaminação desse recurso natural, colocando sua qualidade em risco. Diante disso, o mapeamento de risco à contaminação de aquíferos é uma atividade essencial para promover o conhecimento da área e auxiliar no planejamento territorial e no consumo da água subterrânea.

O risco à contaminação do aquífero é a probabilidade de que a contaminação ocorra, sendo determinado pela interação entre a vulnerabilidade natural do sistema aquífero e o perigo à contaminação (GOERL, KOBIYAMA e PELLERIN, 2012). Portanto, o mapa de risco é resultante do cruzamento dos mapas de vulnerabilidade e de perigo à contaminação do aquífero.

A vulnerabilidade do aquífero diz respeito às suas características de fragilidade naturais em relação à possível exposição à contaminação. Existem diversos métodos para mapear a vulnerabilidade de um aquífero, sendo que, de acordo com Linhares et al. (2014), os mais utilizados são o GOD (Groundwater occurrence; Overall lithology of the unsaturated zone; Depth to the water table) e o DRASTIC (Depth to groundwater, Recharge rate; Aquifer media; Soil media; Topography; Impact of the vadose zone; Hydraulic conductivity).

Entretanto, Foster et al. (2006) afirmam que o método DRASTIC 
tende a resultar em um índice de vulnerabilidade de importância vaga porque a combinação de um excesso de parâmetros ponderados pode gerar uma sobreposição de dados no cálculo do índice de vulnerabilidade, ocasionando em riscos nas tomadas de decisões.

O perigo à contaminação está relacionado com a ameaça ao sistema aquífero, gerada pela presença e o potencial de contaminantes (GOERL, KOBIYAMA e PELLERIN, 2012), de acordo com o uso e ocupação do solo e subsolo. Diante disso, o método POSH (Pollutant Origin; Surcharge Hydraulically) é aplicado com o intuito de definir as principais atividades do município que representam perigo para o aquífero, enquadrando-as entre perigo reduzido, moderado e elevado (PEREIRA JÚNIOR, SOARES e CASTRO, 2015).

A importância estratégica das águas subterrâneas é evidente no município de Chapecó (SC), no qual há atualmente 305 poços perfurados e registrados no Sistema de Informações de Águas Subterrâneas (SIAGAS) que são utilizados para abastecimento doméstico, industrial, animal, na irrigação e em atividades de lazer.

A explotação de águas subterrâneas no município ocorre quase que totalmente no Sistema Aquífero Serra Geral (SASG), que apresenta condições de confinamento entre livre e confinado.

As atividades potencialmente poluidoras na região onde está inserido o município de Chapecó, de acordo com o diagnóstico obtido no PROESC - Projeto Oeste de Santa Catarina (FREITAS,
2003), estão relacionadas com a ocupação da região de forma não sustentável causando desmatamento, erosão do solo, assoreamento dos rios, uso excessivo e não planejado de dejetos suínos em lavouras, a aplicação excessiva de agrotóxicos, falta de tratamento de esgoto, disposição inadequada de lixo e efluentes industriais.

Apesar de o desenvolvimento socioeconômico da região oeste de Santa Catarina depender essencialmente das águas subterrâneas, de acordo com Freitas et al. (2002), até o presente momento não foi elaborada nenhuma avaliação do risco à contaminação do SASG no município de Chapecó (SC).

Diante disso, o objetivo deste trabalho foi mapear a vulnerabilidade, o perigo e o risco à contaminação do SASG no município de Chapecó por meio da aplicação dos métodos GOD, POSH e cruzamento de mapas, respectivamente, viabilizando o planejamento territorial sustentável.

\section{MATERIAIS E MÉTODOS}

\section{1. Área de estudo}

O município de Chapecó possui área de 625,3 km² e está localizado na região oeste do estado de Santa Catarina entre as coordenadas geográficas $27^{\circ} 16^{\prime} 00^{\prime \prime}$ e $26^{\circ} 56^{\prime} 00^{\prime \prime}$ de latitude sul e 52 $52^{\prime} 00^{\prime \prime}$ e $52^{\circ} 19^{\prime} 00^{\prime \prime}$ de longitude a oeste de Greenwich (Figura 1). o Clima subtropical no município caracteriza o verão quente da região, com temperaturas médias anuais de $22{ }^{\circ} \mathrm{C}$ (PANDOLFO et al., 2002).

Figura 1 - Localização do município de Chapecó (SC) e dos poços perfurados

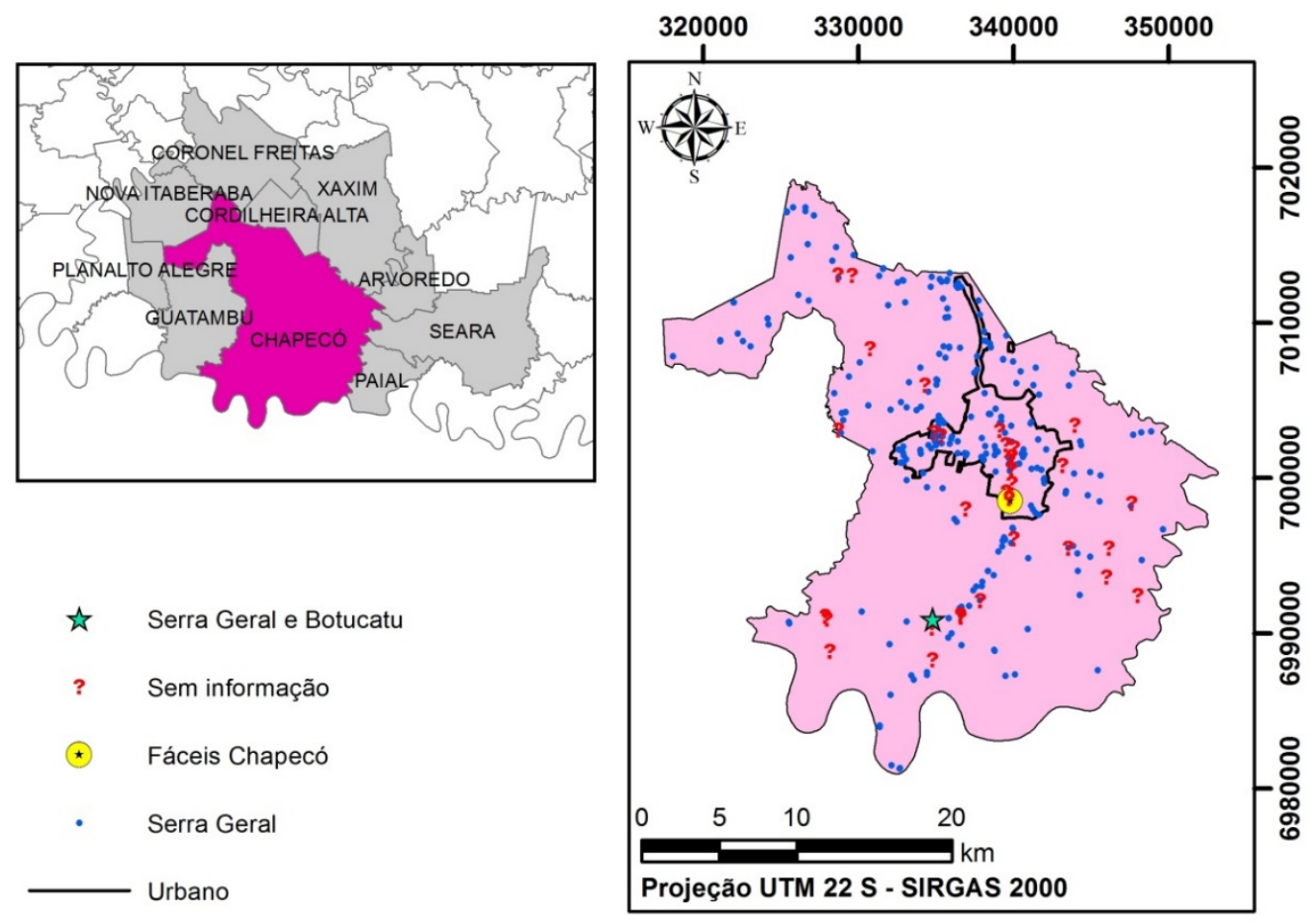

Nota-se que "Sem informação" são os poços que não apresentam formação geológica especificada no Sistema de Informações de Águas Subterrâneas (SIAGAS). 
O município está inserido na Província Hidrogeológica Paraná, que é caracterizada por formações sedimentares, em geral, clásticas, e intrusões e derrames basálticos que atingem espessura de até 7.800 metros. Esta província se destaca por ser uma das melhores províncias hidrogeológicas em termos de produtividade, sendo que nela encontram-se os Sistemas Aquífero Guarani e Serra Geral (SASG) (MENTE, 2008).
Atualmente há 305 poços registrados no SIAGAS, localizados no território do município, sendo que 268 destes estão perfurados no SASG e são utilizados como fonte de abastecimento (Figura 1). A Tabela 1 indica as condições encontradas nos poços de Chapecó (SC), segundo Machado (2013).

Tabela 1 - Características dos poços perfurados no SASG no município de Chapecó (SC)

\begin{tabular}{|c|c|c|c|}
\hline Zona aquífera & Descrição & Vazões prováveis $\left(\mathrm{m}^{3} / \mathrm{h}\right)$ & Nível estático (m) \\
\hline \multirow{2}{*}{ Serra Geral } & $\begin{array}{l}\text { Aquíferos fraturados de maior } \\
\text { potencialidade* }\end{array}$ & 5,0 a 40,0 & 5,0 a 30,0 \\
\hline & $\begin{array}{l}\text { Aquíferos fraturados de menor } \\
\text { potencialidade* }\end{array}$ & 2,0 a 15,0 & 5,0 a 30,0 \\
\hline $\begin{array}{c}\text { Formações Geológicas Permia- } \\
\text { nas e Cretácicas }\end{array}$ & $\begin{array}{c}\text { Aquíferos locais e de pouca ex- } \\
\text { tensão }\end{array}$ & 3,0 a 10,0 & 10,0 a 30,0 \\
\hline
\end{tabular}

O SASG no município é caracterizado pela ocorrência de aquíferos fraturados de rocha basáltica e solo resultante da alteração dessas rochas. Assim, os aquíferos fraturados podem ocorrer em condições semiconfinados e confinados, bem como em porosos livres.

Os aquíferos livres localizam-se na zona de alteração das rochas e sofrem influência do tipo de solo, da espessura da zona alterada, da topografia, do clima e do substrato rochoso (REGINATO, 2003). O nível estático desse aquífero varia de acordo com a precipitação, que conforme Pandolfo et al. (2002) apresenta um valor anual entre 1700 e $1900 \mathrm{~mm}$.

Os aquíferos do tipo semiconfinados e confinados são formados pelas fraturas do maciço rochoso da Formação Serra Geral e, portanto, dependem inteiramente da estruturação dos derrames basálticos (FREITAS, 2003; REGINATO, 2003).

\subsection{Estimativa da vulnerabilidade}

Proposto em 1988 por Foster e Hirata, o método GOD trata-se de um método empírico utilizado na determinação da vulnerabilidade de aquíferos (HIRATA; FERNANDES, 2008) a partir dos parâmetros de grau de confinamento, grau de consolidação dos estratos de cobertura e profundidade da água subterrânea.

\subsubsection{Parâmetro G}

O grau de confinamento do SASG no município de Chapecó foi obtido a partir da interpretação de informações sobre as condições hidrogeológicas e grau de confinamento das zonas aquíferas do Mapa Hidrogeológico de Santa Catarina em escala 1:500.000 (MACHADO, 2013), disponível em arquivo digital.

Tabela 2 - Informações hidrogeológicas das 2 zonas aquíferas identificadas em Chapecó (SC) e utilizadas para interpretação do grau de confinamento

\begin{tabular}{|c|c|c|c|}
\hline Zonas aquíferas & Condições hidrogeológicas & Grau de confinamento & Valor de G \\
\hline Serra Geral & $\begin{array}{l}\text { Aquíferos livres a semiconfinados, regionais e fratura- } \\
\text { dos. }\end{array}$ & Livre a semiconfinado & 0,7 \\
\hline $\begin{array}{c}\text { Formações Geológicas Permianas e } \\
\text { Cretácicas }\end{array}$ & $\begin{array}{l}\text { Aquitardos e aquíferos locais e limitados com porosi- } \\
\text { dade por fraturas. }\end{array}$ & $\begin{array}{l}\text { Semiconfinado a confi- } \\
\text { nado }\end{array}$ & 0,3 \\
\hline
\end{tabular}

Fonte: Adaptado de Machado (2013)

- Informação obtida na tabela de atributos do arquivo digital do mapa;

* Informação obtida por meio de interpretação do relatório Machado (2013).

A zona aquífera Serra Geral apresenta condição intermediária de confinamento, ou seja, de livre a semiconfinado. Então, o parâmetro G desta zona aquífera foi calculado por meio da média aritmética entre os valores correspondentes a aquíferos semiconfinados $(G=0,4)$ e livres não cobertos $(G=1,0)$ (Tabela 2$)$.

A zona aquífera das Formações Geológicas Permianas e Cretácicas não apresenta nenhuma definição direta a respeito do grau de confinamento na tabela de atributos.

Entretanto, de acordo com Machado (2013), nesta zona de aquíferos pouco produtivos há a ocorrência de derrames basálticos pouco fraturados e litologias que não favorecem a produção de água. Além disso, esta zona possui pequena importância hidrogeológica local devido à presença de aquitardos e aquíferos pobres, relacionados a condições morfológicas desfavoráveis (MACHADO, 2013).
Diante disso, para a zona aquífera das Formações Geológicas Permianas e Cretácicas, adotou-se um grau de confinamento de semiconfinado a confinado e, sendo assim, o parâmetro $G$ foi calculado pela média aritmética entre os valores correspondentes a aquíferos semiconfinados $(G=0,4)$ e confinados $(G=0,2)$ (Tabela 2).

\subsubsection{Parâmetro 0}

As informações acerca da ocorrência de estratos de cobertura foram obtidas no Mapa de Solos do Estado de Santa Catarina, elaborado na escala 1:250.000 (EMBRAPA, 2004). O mapa de solos do município é constituído por 16 unidades de mapeamento (Figura 2) que podem apresentar um ou mais tipos de solo com suas respectivas características de textura e profundidade (Tabela 3). 
Para determinar o parâmetro 0 , além do grau de consolidação da zona vadosa ou camada confinante e suas características litológicas, que são as características previstas no método GOD, considerou-se também a profundidade do solo.
A inclusão da profundidade na determinação do parâmetro 0 se justifica pelo fato de que a profundidade corresponde à distância que o contaminante percorreria até alcançar o aquífero, caso se deslocasse verticalmente.

Figura 2 - Unidades de mapeamento de solos de Chapecó (SC)

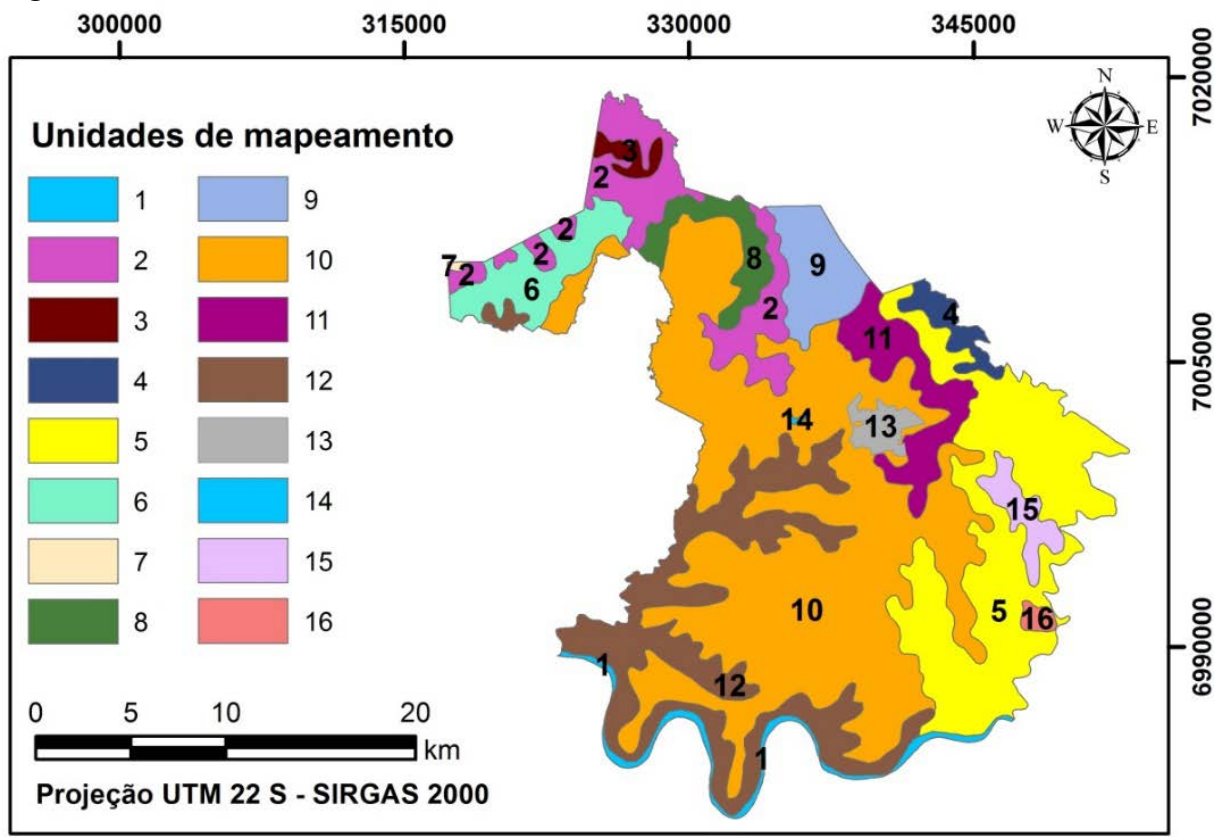

Fonte: Adaptado de EMBRAPA (2004)

Tabela 3 - Tipos de solos constituintes das unidades de mapeamento do município de Chapecó (SC)

\begin{tabular}{|c|c|c|c|}
\hline $\begin{array}{l}\text { Unidade de mapea- } \\
\text { mento }\end{array}$ & Solo 1 & Solo 2 & Solo 3 \\
\hline 1 & Corpo d'água & Corpo d'água & Corpo d'água \\
\hline 2 & Cambissolo* 4 & Solos Litólicos" $\diamond$ & Terra Roxa Estruturada $\circ$ \\
\hline 4 & Terra Roxa Estruturada $\circ$ & Cambissolo* 4 & Solos Litólicos" 4 \\
\hline 5 & Cambissolo* 4 & Solos Litólicos" 4 & - \\
\hline 6 & Terra Roxa Estruturada ○ & - & - \\
\hline 8 & Terra Roxa Estruturada $\bullet$ & - & - \\
\hline 9 & Latossolo Roxo $\circ$ & - & - \\
\hline 10 & Latossolo Bruno/Vermelho ‘ & - & - \\
\hline 11 & Terra Roxa Estruturada ○ & Cambissolo* 4 & - \\
\hline 12 & Cambissolo 4 & Solos Litólicos" $\diamond$ & Terra Roxa Estruturada $\circ$ \\
\hline 13 & Urbano & Urbano & Urbano \\
\hline 14 & Corpo d'água & Corpo d'água & Corpo d'água \\
\hline 16 & Terra Roxa Estruturada $\bullet$ & Cambissolo: 4 & Solos Litólicos" 4 \\
\hline
\end{tabular}

*Nota: Profundidade dos tipos de solo: •: <60 cm; *: entre 60 e $150 \mathrm{~cm}$; ‘: > $150 \mathrm{~cm}$. Textura dos tipos de solo: $\bullet:$ siltosa; ‘: argilosa; $:$ muito argilosa. Fonte: Adaptado de EMBRAPA (2004)

Diante disso, o parâmetro 0 final (Of) foi calculado de acordo com a Equação 1, e os valores adotados encontram-se na Tabela 4.

$O f=\frac{\left(O t_{1}+O p_{1}\right)+\left(O t_{2}+O p_{2}\right)+\ldots+\left(O t_{n}+O p_{n}\right)}{2 \cdot n}$
Onde Of é o valor final de 0 para cada unidade de mapeamento; Ot é o valor de 0 atribuído de acordo com a textura de cada tipo de solo presente na unidade de mapeamento; Op é o valor de 0 atribuído conforme o intervalo de profundidade de cada tipo de solo presente na unidade de mapeamento; e $n$ é o número de tipos de solo presentes na unidade de mapeamento. 
Tabela 4 - Composição do valor final de Of a partir de valores parciais referentes à profundidade e textura.

\begin{tabular}{|c|c|c|c|c|c|}
\hline Profundidade $(\mathrm{cm})$ & Op & Justificativa* & Textura & $O t$ & Justificativa \\
\hline$<60$ & 1,0 & $\begin{array}{l}\text { Capacidade de atenua- } \\
\text { ção muito baixa }\end{array}$ & Siltosa & 0,5 & Valor proposto pelo método GOD \\
\hline 60 a 150 & 0,8 & $\begin{array}{c}\text { Capacidade de atenua- } \\
\text { ção baixa }\end{array}$ & Argilosa & 0,4 & Valor proposto pelo método GOD \\
\hline$>150$ & 0,5 & $\begin{array}{l}\text { Capacidade de atenua- } \\
\text { ção mediana }\end{array}$ & Muito Argilosa & 0,3 & $\begin{array}{l}\text { Textura "muito argilosa" tende a } \\
\text { apresentar efeito de atenuação } \\
\text { maior do que textura "Argilosa" }\end{array}$ \\
\hline
\end{tabular}

Fonte: *Adaptado de Lopes (2012)

Destaca-se que o Mapa de Solos do Estado de Santa Catarina possui três unidades de mapeamento inseridas na área de estudo que não se caracterizam por tipo de solo, sendo duas referentes a corpos d'água e uma representando as áreas urbanas. Nestes casos, o valor atribuído ao parâmetro Of foi igual a 1,0.

\subsubsection{Parâmetro $D$}

Para a atribuição dos valores do parâmetro $D$ foi levado em consideração o nível estático, pois, de acordo com Reginato (2003), os sistemas de aquíferos livres, semiconfinados e confinados estão interligados, sendo evidente que as mesmas águas que circulam nos aquíferos livres alimentam os aquíferos semiconfinados e confinados por meio das fraturas. Diante disso, podese afirmar que contaminação das águas dos aquíferos livres, pode interferir diretamente na qualidade das águas dos aquíferos semiconfinados e confinados.
A distância até o lençol freático do Sistema Aquífero Serra Geral foi obtida no banco de dados do SIAGAS (Figura 3).

Identificaram-se no município 305 poços registrados no SIAGAS, entretanto, aqueles que não apresentavam dados de Nível Estático (NE) e informação sobre a formação geológica foram excluídos, restando 205 poços cujas informações de nível estático foram interpoladas pelo método Inverse Distance Weighted (IDW) que foi o que manteve o intervalo de variação dos níveis estáticos dos poços na área do município mais próximo ao medido.

Apesar das informações serem de nível estático, é possível perceber influência de rebaixamento onde há maior concentração de poços (Figuras 1 e 3).

Figura 3 - Distribuição dos níveis estáticos

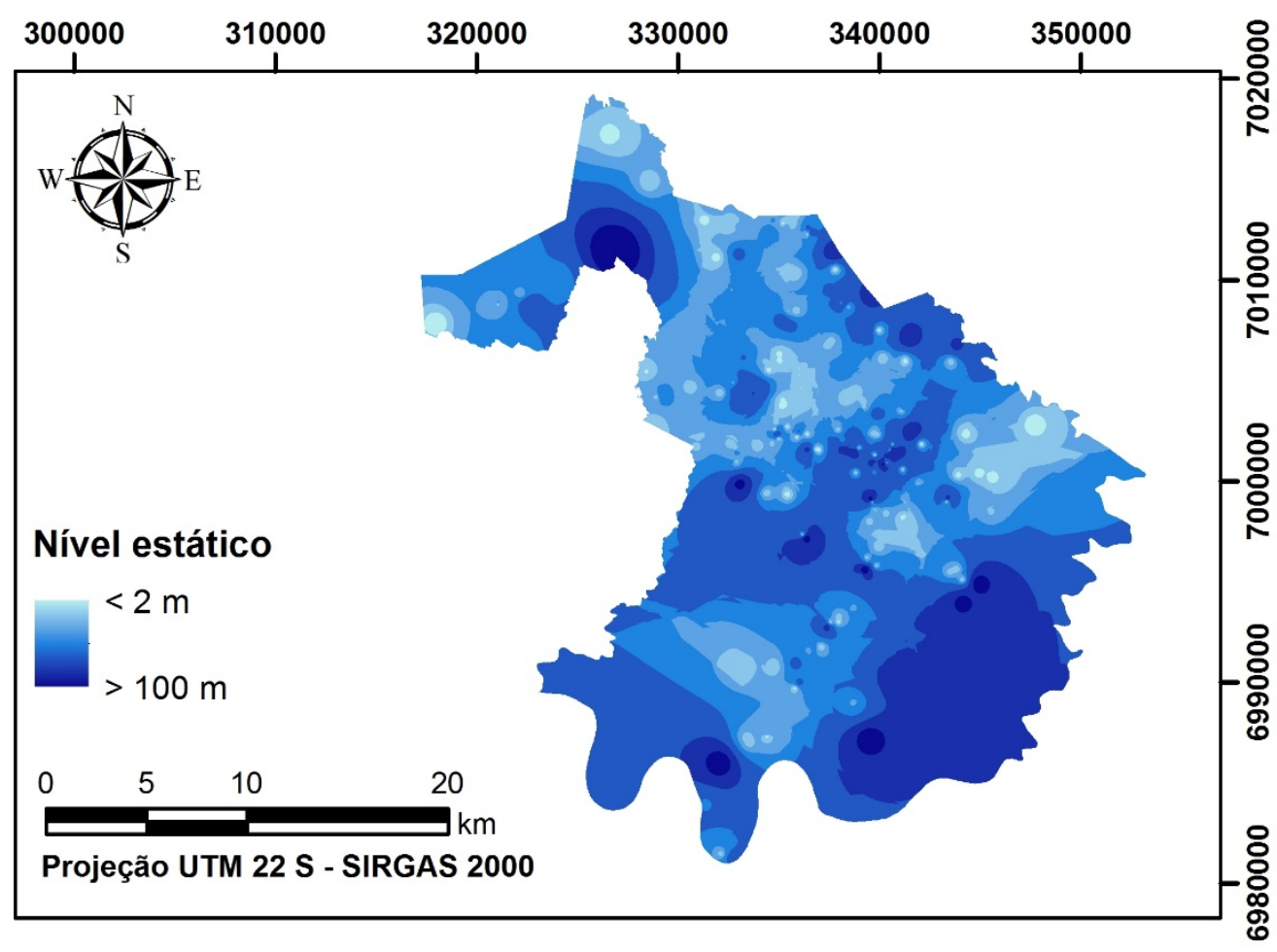

Além disso, a profundidade de solo poderia ser utilizada para inferir sobre a distância da superfície até o topo do aquífero confinado. Porém, não se dispõe de informações com detalhes suficientes para tal consideração e a influência da profundidade do solo foi contabilizada no parâmetro 0 .
Os valores de $D$ do método GOD possuem cinco intervalos de classificação, entretanto adotou-se a classificação sugerida por Reginato e Ahlert (2013), no intuito de representar de maneira mais discretizada a variabilidade do NE e sua relação com a vulnerabilidade (Tabela 5). 
Tabela 5 - Valores adotados de $D$ de acordo com a profundidade do Nível Estático

\begin{tabular}{|c|c|c|c|c|c|c|c|}
\hline Profundidade NE (m) & $>100$ & 50 a 100 & 20 a 50 & 10 a 20 & 5 a 10 & 2 a 5 & $<2$ \\
\hline Valor de $D$ & 0,4 & 0,5 & 0,6 & 0,7 & 0,8 & 0,9 & 1 \\
\hline
\end{tabular}

Fonte: Adaptado de Reginato e Ahlert (2013)

\subsubsection{Mapeamento da vulnerabilidade}

Após a atribuição dos valores de cada um dos parâmetros G, 0 e D, realizou-se a análise e processamento dos dados em ambiente de Sistema de Informação Geográfica (SIG), no sistema de referência SIRGAS 2000 projeção UTM zona 22 S. Os mapas foram multiplicados por meio da ferramenta "Raster Calculator" do ArcGIS 10.3, obtendo-se assim o mapa da vulnerabilidade natural do Sistema Aquífero Serra Geral no município de Chapecó (SC), que foi classificado de acordo com o método GOD.

\subsection{Mapeamento de perigo e risco à contaminação}

As principais fontes de contaminações consideradas na aplicação de POSH foram baseadas no mapa de uso e ocupação da terra elaborado para o município (Figura 4) a partir de imagens do satélite Landsat 8, datadas em 07 de abril de 2016, obtidas gratuitamente no banco de dados do United States Geological Survey - USGS (Tabela 6).

Figura 4 - Mapa do uso e ocupação da terra no município de Chapecó (SC)

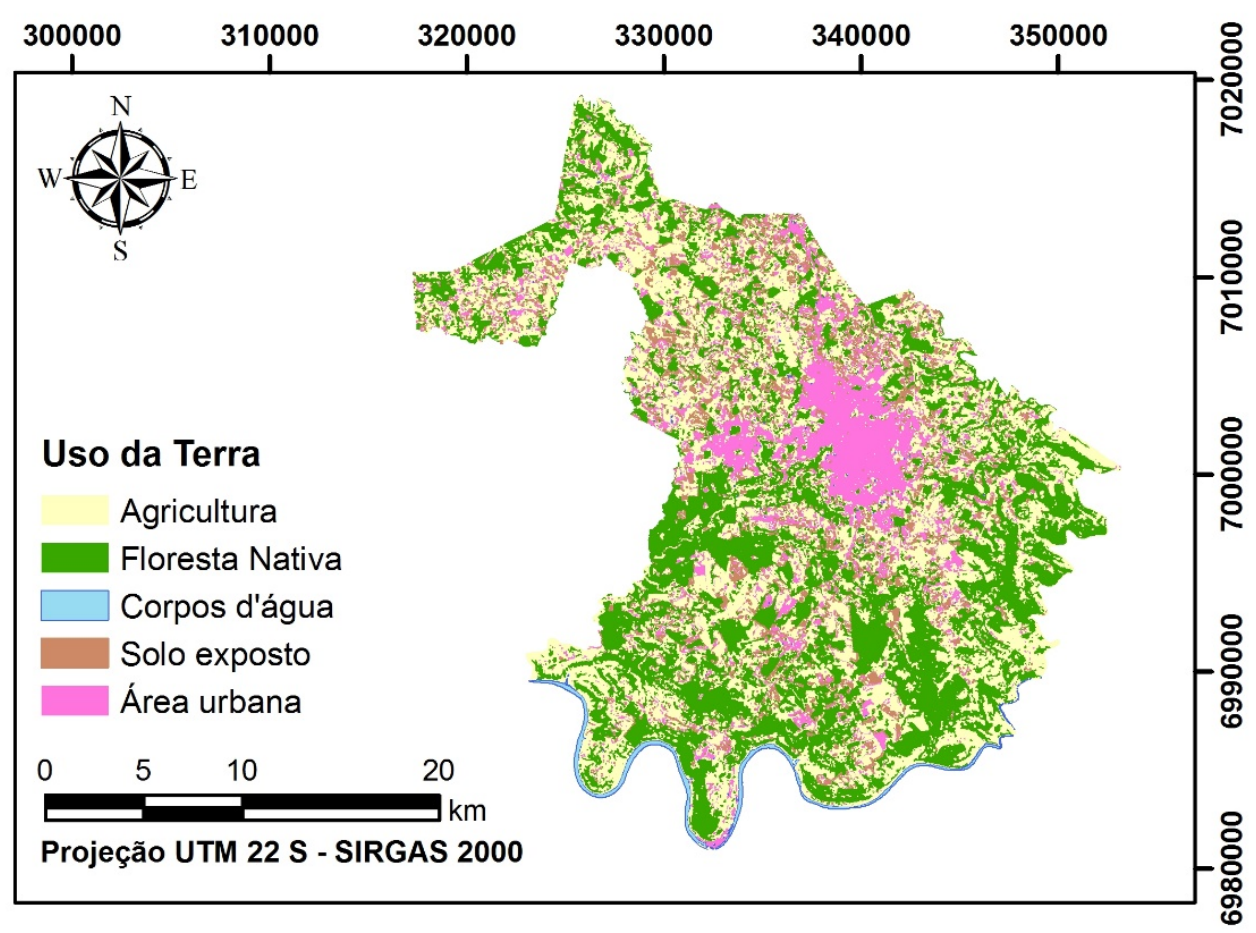

Tabela 6 - Distribuição em porcentagem e área das classes do uso e ocupação da terra

\begin{tabular}{crr}
\hline Classe & (\%) & \multicolumn{1}{c}{$\mathbf{k m}^{2}$} \\
\hline Agricultura & 42,00 & 262,60 \\
Floresta nativa & 38,75 & 242,31 \\
Área urbana & 15,11 & 94,50 \\
Solo exposto & 3,03 & 18,94 \\
Corpos d'água & 1,11 & 6,94 \\
\hline
\end{tabular}

Além do uso e ocupação da terra, as principais fontes pontuais potencialmente poluidoras e seus diâmetros de dispersão (dp) também foram localizados e incluídos na análise: dois cemitérios do município $(\mathrm{dp}=200 \mathrm{~m}$ ); dez postos de combustíveis ( $\mathrm{dp}$ $=200 \mathrm{~m})$; e 302 poços perfurados $(\mathrm{dp}=100 \mathrm{~m})$ no município, dos 305 presentes na área de estudo, pois os outros três não possuíam informações de coordenadas geográficas necessárias para esta análise.

A classe "Floresta nativa" se caracteriza por ser uma área sem influência das ações antrópicas e, por isso, não oferece risco de contaminação às águas subterrâneas, mas sim coopera em sua proteção e conservação. Por isso, acrescentou-se o nível qualitativo "Nenhum" ao método POSH nos quais as fontes foram enquadradas. (Tabela 7).

O mapa de risco à contaminação foi obtido por meio do cruzamento entre o mapa de vulnerabilidade natural (método GOD) e o mapa de perigo (método POSH) de acordo com a Tabela 8. 
Tabela 7 - Níveis qualitativos de POSH para fontes difusas e pontuais

\begin{tabular}{lc}
\hline \multicolumn{1}{c}{ Fonte } & Nível de perigo \\
\hline Área urbana & Elevado \\
Solo exposto & Moderado \\
Agricultura & Elevado \\
Floresta nativa & Nenhum \\
Corpos d'água & Elevado \\
Cemitérios (diâmetro de $200 \mathrm{~m}$ ) & Reduzido \\
Postos de combustível (diâmetro de $200 \mathrm{~m}$ ) & Moderado \\
Poços (diâmetro de $100 \mathrm{~m}$ ) & Reduzido \\
\hline
\end{tabular}

Tabela 8 - Risco resultante da interação entre os níveis de vulnerabilidade natural e perigo de contaminação

\begin{tabular}{|l|lllll|}
\cline { 2 - 5 } \multicolumn{1}{c|}{} & \multicolumn{5}{c|}{ VULNERABILIDADE } \\
\hline PERIGO & Insignificante & Baixa & Média & Alta & Extrema \\
Renhum & Nenhum & Muito Baixo & Baixo & Médio & Alto \\
Moderado & Muito baixo & Baixo & Médio & Alto & Muito Alto \\
Elevado & Baixo & Médio & Alto & Muito Alto & Elevado \\
& Médio & Alto & Muito Alto & Elevado & Muito Elevado \\
\hline
\end{tabular}

\section{RESULTADOS E DISCUSSÕES}

\subsection{Mapeamento da vulnerabilidade - método GOD}

Em relação ao grau de confinamento, cerca de $63 \%$ da área do município possui valor de $\mathrm{G}$ igual 0,7 (Figura 5a). Isso acontece devido ao fato de que a zona aquífera Serra Geral é composta por aquíferos livres não cobertos e semiconfinados e, por isso, está mais suscetível à contaminação.

Figura 5 - Parâmetros do método de GOD do SASG. (a) Grau de confinamento (G); (b) Ocorrência de estratos de cobertura; e (c) Distância até o lençol freático

(a)

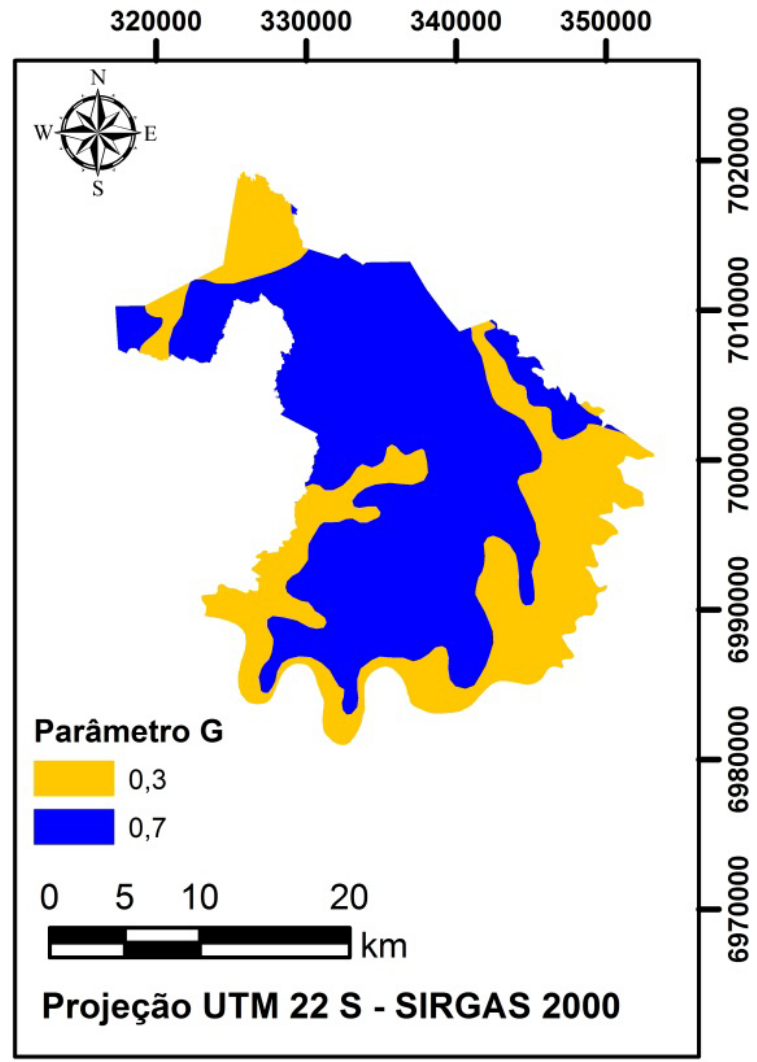

(b)

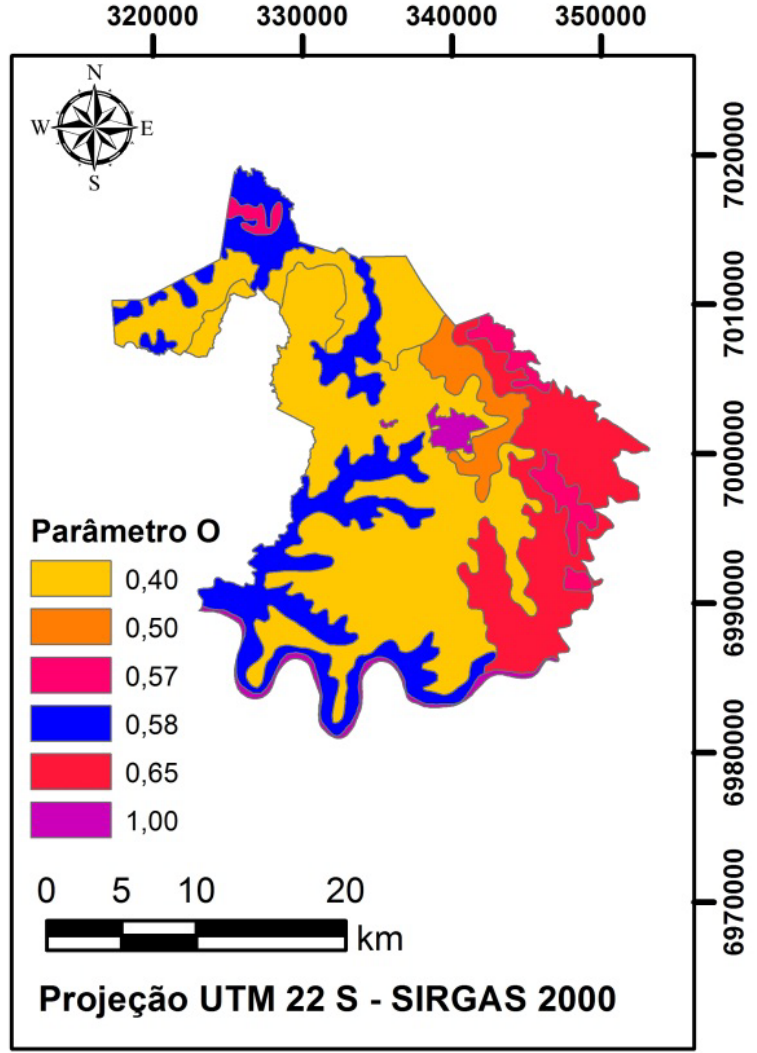


(c)

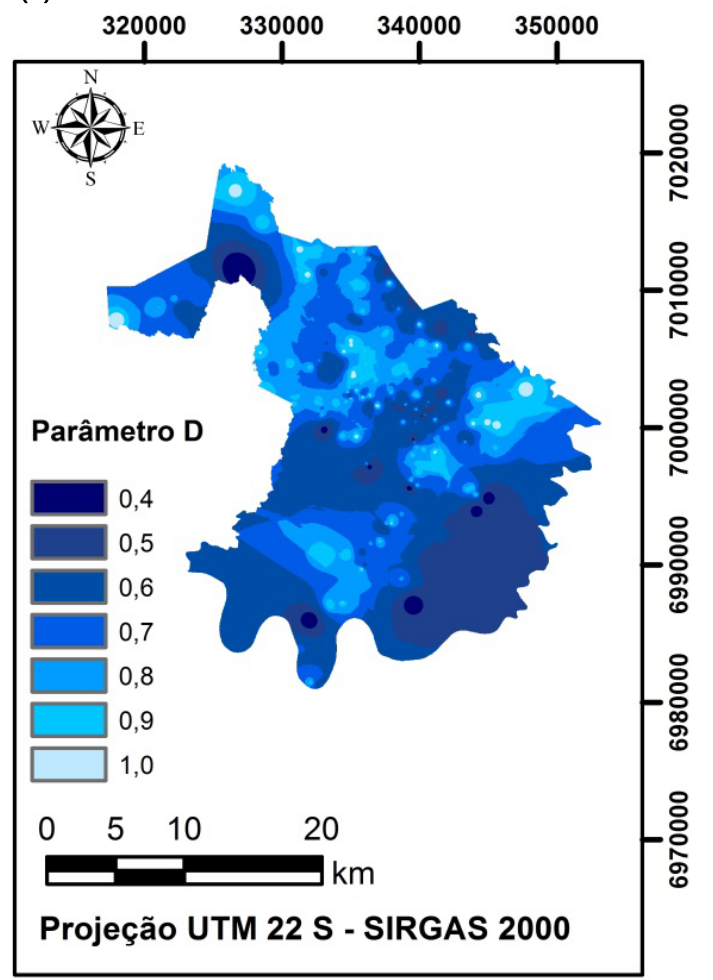

Os restantes 37\% correspondem à zona aquífera das Formações Geológicas Permianas e Cretácicas, compostas por aquitardos e aquíferos locais e limitados. Os aquitardos se caracterizam por impedirem ou dificultarem o movimento das águas subterrâneas, e por isso, apresentam um valor menor na vulnerabilidade natural.

Os valores de 0 evidenciam a influência da textura e profundidade, na qual os tipos de solo Latossolo Roxo, Latossolo Bruno Vermelho e Terra Roxa Estruturada possuem a textura mais fina e profundidades maiores (Tabela 4), o que promove o menor valor de vulnerabilidade com 0 igual a 0,4 (Figura 5b).

Já a presença dos tipos de solo Cambissolo e Solos Litólicos aumentam a vulnerabilidade do aquífero, por apresentarem profundidade menor e possuírem textura mais grosseira com maior condutividade hidráulica e menor potencial de retenção.

As áreas com maior valor de D no município de Chapecó (SC) se encontram na porção central, exatamente na região de seu pe- rímetro urbano (Figura 5c).

O Sistema Aquífero Serra Geral no município de Chapecó (SC) apresenta vulnerabilidade gerada pelo método GOD entre insignificante e alta, com o predomínio de baixa vulnerabilidade (Figura 6).

Pode-se perceber no mapa que no perímetro urbano, com contorno destacado no mapa pela linha preta, é onde ocorrem as áreas de vulnerabilidade alta, entretanto sua influência na vulnerabilidade total do SASG é pouco significativa.

Com isso, observa-se que as características naturais de grau de confinamento, ocorrência de estratos de cobertura e distância até o lençol freático favorecem a proteção do SASG. Sendo assim, é recomendável que estas características naturais sejam conservadas para que esta condição se estenda ao longo dos anos sendo necessário que o ordenamento territorial ocorra de maneira planejada. 
Figura 6 - Mapa do índice de vulnerabilidade do SASG

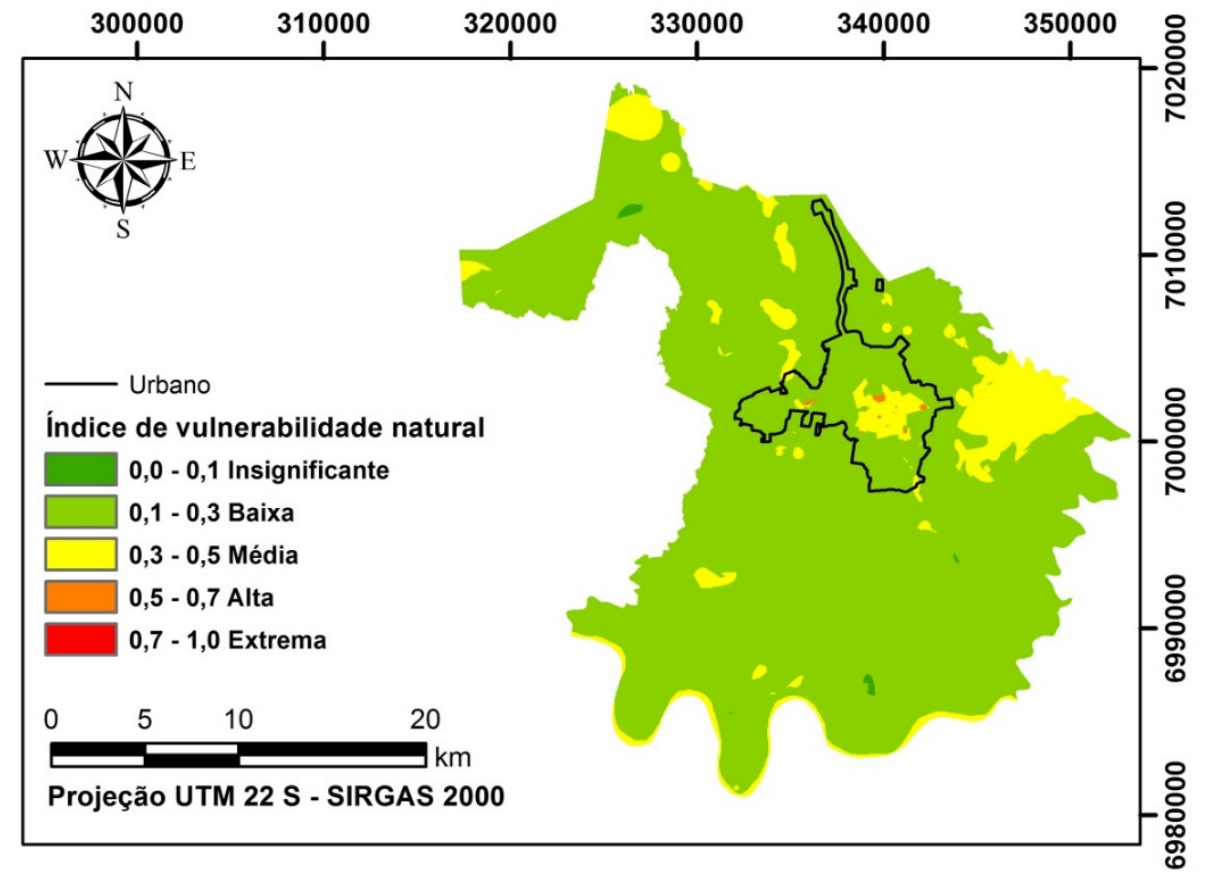

\subsection{Mapeamento do perigo método POSH}

No mapa do perigo à contaminação é possível identificar que o grau de perigo que ocupa maior área no município é elevado (Figura 7). Esse resultado está associado com os usos da terra solo de área urbana, corpos d'água e com a atividade de agricultura, sendo que a agricultura possui a maior influência neste peso, pois representa o uso e ocupação da terra que abrange a maior área do município.

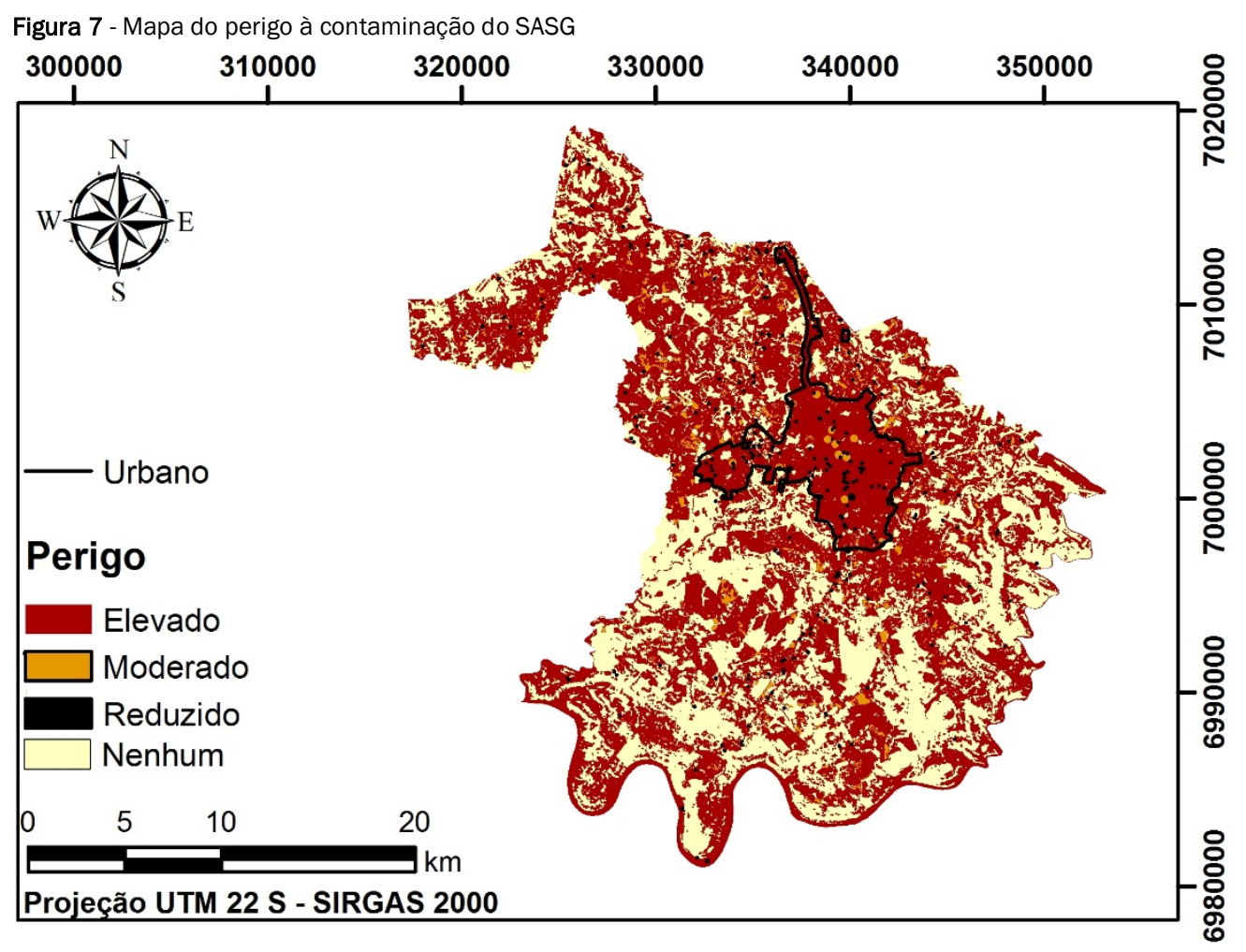

\subsection{Mapeamento de risco}

Pode-se observar que a maior influência no resultado de alto risco está associada ao uso e ocupação da terra, caracterizado principalmente pela atividade agrícola e pela urbanização da área de estudo (Figura 8). 
Diante disso, destaca-se a importância que o ordenamento territorial do município ocorra a partir de um planejamento adequado, pois, apesar de no município a vulnerabilidade à contaminação ser baixa, os riscos são altos (Tabela 9).

A vulnerabilidade do aquífero tanto no município, quanto no perímetro urbano se desenvolve de forma homogênea ao longo da área de Chapecó (SC), onde 90,11\% da área total do municí- pio e $83,88 \%$ do perímetro urbano são baixas. Sendo assim, pode-se afirmar que as características naturais do aquífero relacionadas com o grau de confinamento da água subterrânea, com a ocorrência dos estratos de cobertura e com a distância da superfície até a água subterrânea, colaboram para a atenuação natural de possíveis contaminações do SASG de Chapecó (SC).

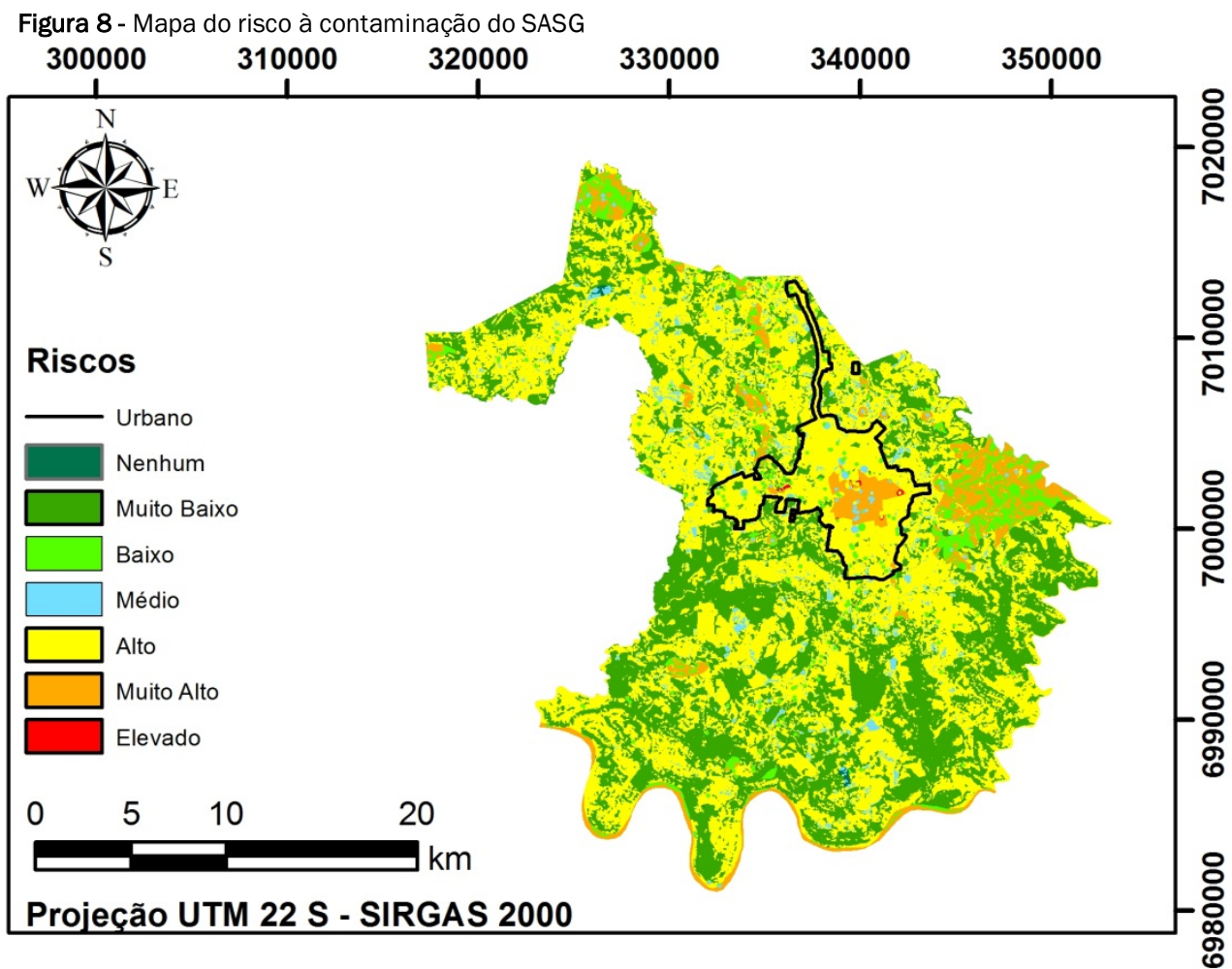

\begin{tabular}{|c|c|c|}
\hline VULNERABILIDADE & Município (\%) & Perímetro urbano (\%) \\
\hline Insignificante & 0,18 & 0,00 \\
\hline Baixa & 90,11 & 83,88 \\
\hline Média & 9,62 & 14,97 \\
\hline Alta & 0,09 & 1,14 \\
\hline Extrema & 0,00 & 0,00 \\
\hline \multicolumn{3}{|l|}{ PERIGO } \\
\hline Nenhum & 38,23 & 5,81 \\
\hline Reduzido & 1,41 & 6,69 \\
\hline Moderado & 3,34 & 3,69 \\
\hline Elevado & 57,02 & 83,80 \\
\hline \multicolumn{3}{|l|}{ RISCO } \\
\hline Nenhum & 0,08 & 0,00 \\
\hline Muito Baixo & 34,99 & 5,53 \\
\hline Baixo & 4,43 & 5,28 \\
\hline Médio & 3,42 & 4,30 \\
\hline Alto & 51,15 & 71,26 \\
\hline Muito Alto & 5,88 & 13,07 \\
\hline Elevado & 0,04 & 0,56 \\
\hline
\end{tabular}

\section{CONSIDERAÇÕES FINAIS}

O Sistema Aquífero Serra Geral (SASG) é o mais importante na região oeste de Santa Catarina e, em especial, no município de Chapecó (SC), onde é consideravelmente explotado.
O SASG no município de Chapecó (SC) possui, predominantemente, baixa vulnerabilidade à contaminação, elevado perigo à contaminação, e alto risco à contaminação, sujeitando 51,15\% da área do município e $71,26 \%$ da área do perímetro urbano a esta condição de risco. 
Diante disso, destaca-se a necessidade de que a ocupação do município seja planejada, para que os riscos à contaminação não se elevem. Para isto, recomenda-se que as novas instalações de fontes potencialmente poluidoras, ou seja, atividades que apresentem algum tipo de perigo à contaminação do aquífero, como é o caso de novas indústrias, atentem-se para o mapa de vulnerabilidade do SASG de Chapecó (SC), sendo que estas devem ser localizadas preferencialmente nas áreas de baixa vulnerabilidade, evitando áreas de média e alta vulnerabilidade.

\section{REFERÊNCIAS}

EMBRAPA. Solos do Estado de Santa Catarina. Boletim de Pesquisa e Desenvolvimento, n. 46. Rio de Janeiro: EMBRAPA Solos, 2004.

FOSTER, S. et al. Proteção da qualidade da água subterrânea: um guia para empresas de abastecimento de água, órgãos municipais e agências ambientais. São Paulo: Servmar, 2006. 104 p.

FREITAS, M.A. Diagnóstico dos recursos hídricos subterrâneos do oeste do Estado de Santa Catarina. Projeto Oeste de Santa Catarina. Porto Alegre: CPRM/SDM-SC/SDA-SC/EPAGRI, 2003. p.100.

FREITAS, M.A. et al. Água subterrânea: um recurso vital para o Oeste Catarinense. In: CONGRESSO BRASILEIRO DE ÁGUAS SUBTERRÂNEAS, 12., 2002, Florianópolis. Anais eletrônicos... Florianópolis: ABAS, 2002. p. 1-8.

GOERL, R.F; KOBIYAMA, M; PELLERIN, J.R.G.M. Proposta metodológica para mapeamento de áreas de risco a inundação: estudo de caso do município de Rio Negrinho - SC. Boletim de Geografia, Maringá, v.30, n.1, p.81-100, 2012
HIRATA, R.; FERNANDES, A.J. Vulnerabilidade à poluição de aquíferos. In: FEITOSA, F.A.C. et al. (Org.) Hidrogeologia: conceitos e aplicações. 3. ed. rev. e ampl. Rio de Janeiro: CPRM/LABHID, 2008. p. 405-424.

LINHARES, F.M. et al. Avaliação da vulnerabilidade e do risco à contaminação das águas subterrâneas da bacia hidrográfica do Rio Gramame (PB). Sociedade \& Natureza, Uberlândia, v. 26, n.1, p.139-157, 2014.

LOPES, A.R.B.C. Recursos hídricos e uso da terra na bacia do Rio do Peixe/SC, mapeamento das áreas de vulnerabilidade e risco de contaminação do Sistema Aquífero Serra Geral. 317 f. Tese (Doutorado em Geografia) - Universidade Federal de Santa Catarina, Florianópolis, 2012.

MACHADO, J.L.F. Mapa hidrogeológico do estado de Santa Catarina: escala 1:500.000. Porto Alegre: CPRM, 2013.

MENTE, A. A água subterrânea no Brasil. In: FEITOSA, F.A.C. et al. (Org.) Hidrogeologia: conceitos e aplicações. 3. ed. rev. e ampl. Rio de Janeiro: CPRM: LABHID, 2008, p. 31-48.

PANDOLFO, C.; BRAGA, H.J.; SILVA JR, V.P. da; MASSIGNAM, A.M., PEREIRA, E.S.; THOMÉ, V.M.R.; VALCI, F.V. Atlas climatológico do Estado de Santa Catarina. Florianópolis: Epagri, 2002. CD-Rom.

PEREIRA JÚNIOR, L.C.; SOARES, H.L.T.; CASTRO, S.S. Vulnerabilidade natural e risco de contaminação do aquífero Bauru no município de Rio Verde - GO. Águas Subterrâneas, v.29, n.2, p.129-145, 2015.

REGINATO, P.A.R. Integração de dados geológicos para prospecção de aquíferos fraturados em trecho da bacia hidrográfica Taquari-Antas (RS). 276 f. Tese (Doutorado em Engenharia) - Universidade Federal do Rio Grande do Sul, Porto Alegre, 2003.

REGINATO, P.A.R; AHLERT, S. Vulnerabilidade do sistema aquífero Serra Geral na região nordeste do estado do Rio Grande do Sul. Águas Subterrâneas, v. 27, n.2, p.32-46, 2013. 